\title{
Matching salt intake to physiological need in rats using foraging protocols
}

N.E. Rowland

\section{Correspondence}

N.E. Rowland

Department of Psychology

University of Florida

Gainesville, FL 32611-2250

USA

nrowland@ufl.edu

Presented at the International

Symposium of Neuroendocrinology

"Neuroendocrine control of body

fluid homeostasis: past, present

and future". Ribeirão Preto, SP,

Brazil, September 1-3, 2006.

Received October 11, 2006 Accepted February 1, 2007 $\ldots \ldots \ldots \ldots \ldots \ldots \ldots$
Department of Psychology, University of Florida, Gainesville, FL, USA

\begin{abstract}
Several studies of the quantitative relationship between sodium need and sodium intake in rats are reviewed. Using acute diuretic treatment $24 \mathrm{~h}$ beforehand, intake matches need fairly accurately when intake is spread out in time by using a hypotonic solution of $\mathrm{NaCl}$. In contrast, using a hypertonic solution, intake is typically double the need. Using the same diuretic treatment, although the natriuresis occurs within $\sim 1$ $\mathrm{h}$, the appetite appears only slowly over $24 \mathrm{~h}$. Increased plasma levels of aldosterone parallel the increased intake; however, treatment with metyrapone blocks the rise in aldosterone but has no effect on appetite. Satiation of sodium appetite was studied in rats using sodium loss induced by chronic diuretic treatment and daily salt consumption sessions. When a simulated foraging cost was imposed on $\mathrm{NaCl}$ access in the form of a progressive ratio lever press task, rats showed satiation for $\mathrm{NaCl}$ (break point) after consuming an amount close to their estimated deficit. The chronic diuretic regimen produced hypovolemia and large increases in plasma aldosterone concentration and renin activity. These parameters were reversed to or toward nondepleted control values at the time of behavioral satiation in the progressive ratio protocol. Satiation mechanisms for sodium appetite thus do appear to exist. However, they do not operate quantitatively when concentrated salt is available at no effort, but instead allow overconsumption. There are reasons to believe that such a bias toward overconsumption may have been beneficial over evolutionary time, but such biasing for salt and other commodities is maladaptive in a resource-rich environment.
\end{abstract}

\section{Introduction}

In the laboratory, sodium appetite most usually is studied using rats and access to hypertonic solutions of $\mathrm{NaCl}$ that normally would be unpalatable. This ensures that the behavior is 'motivated' because, under comparable control conditions, intake would be minimal. Several models of sodium appetite have been developed. Some of these use natural sodium deficiency while others emulate one or more of the hormonal conditions
Key words

- Furosemide

- Progressive ratio

- Aldosterone

- Satiation
- Sodium depletion associated with natural deficiency, such as elevated circulating mineralocorticoid and/ or angiotensin II concentrations (1). Such models and procedures have focused largely on the initiating conditions for sodium appetite, and there are relatively few studies on the termination of sodium appetite. Only depletion models, in which there is a true and quantifiable need, allow us to assess whether the appetite (i.e., amount consumed in a designated elapsed time) is commensurate with the need. 
The most widely used model of sodium depletion was introduced by Jalowiec (2) and involves administration of the loop diuretic, furosemide. This produces a quite rapid (complete within $2 \mathrm{~h}$ ) diuresis of near isotonic urine, and adult rats typically lose $\sim 2 \mathrm{mEq}$ of sodium during this time. The sodium appetite that develops as a result of this abrupt depletion has several important characteristics: it is taste-guided and relatively specific for the taste of sodium; it matures over several hours to reach a maximal level after 12-24 $\mathrm{h}$ (provided that the animals receive sodium-free food so they cannot replete in the interim); the maximal level reached is excessive, typically two to three times the actual sodium loss.

The first of these characteristics is most likely due to the presence of specific sodium-sensitive fibers in the gustatory system (3). The second is probably a result of genomic or other non-immediate actions of

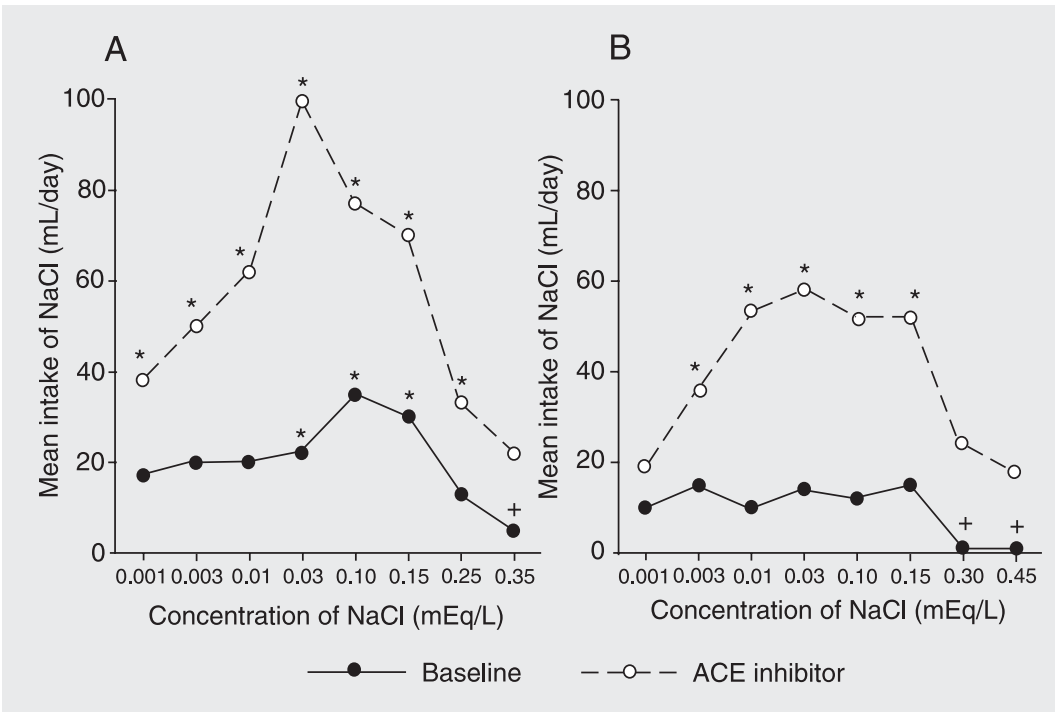

Figure 1. Mean daily intake of $\mathrm{NaCl}$ solution of various concentrations, available in a twobottle choice with water. Data are averaged over several days for each concentration. $A$, Redrawn from Fregly (8) Figure 1, shows data from female Sprague-Dawley (SD) rats under baseline conditions or with the angiotensin-converting enzyme (ACE) inhibitor captopril added to the food $(1.05 \mathrm{~g} / \mathrm{kg})$. ${ }^{*} P<0.05$ higher, ${ }^{+} \mathrm{P}<0.05$ lower than concurrent water intakes (the latter are not shown; $t$-test). Captopril induced a net preference for $\mathrm{NaCl}$ at both low and high concentrations compared to baseline. $B$, Redrawn from Rowland and Fregly (6), shows data from male Fisher 344 rats under baseline conditions and when the ACE inhibitor, ramipril $(0.05 \mathrm{~g} / \mathrm{kg})$, was added to the food. Note that ramipril induced a net preference for $\mathrm{NaCl}$ across most of the concentration range, and that the ACE-induced increase from baseline was comparable to that in SD rats shown in A. the hormones that are elevated soon after sodium loss (1), and the third has no good explanation and is the topic of the present review.

Sodium appetite has often been considered a 'model drive' (4) because of its relatively simple physiological underpinnings and few commodities that will satisfy that appetite. Additionally, sodium depletion can be quantified accurately and any repletion of that deficit likewise can be measured easily. This is due in part to the fact that there is no significant storage for sodium in the body, a situation that is considerably simpler than the relation between food and energy status. Thus, most of the sodium is in a relatively exchangeable form - extracellular fluid - that is subject to rapid loss, as with furosemide, and gain, as after drinking sodium salts. This makes it an ideal system in which to study whether the induced appetite is in fact matched to physiological need. We already know, from the list in the previous paragraph, that this is not the case - depleted rats consume excessive amounts of sodium, at least under some conditions. We will consider three conditions that affect the amount of sodium consumed, and therefore the matching of intake to need: concentration, time, and effort.

\section{Concentration of sodium offered}

Animals show characteristic preferenceaversion intake functions as a function of the concentration of sodium salt (usually $\mathrm{NaCl}$ ) offered. In the absence of sodium depletion, these functions differ between species and between strains within a species (5-7), and sometimes between brief and long access tests that assess taste only and taste plus post-ingestive effects, respectively. Functions for two strains of rats tested in 24-h two-bottle choice tests (water and salt) are shown in Figure 1 (redrawn from original data published by Fregly (8) and Rowland and Fregly (6)). Under need-free conditions, 
Sprague-Dawley rats show preferences for $\mathrm{NaCl}$ in the $30-150 \mathrm{mM}$ range, and aversion at $350 \mathrm{mM}$, while Fisher 344 rats show no preference and only an aversion above 150 $\mathrm{mM}$. In contrast, during chronic dietary administration of angiotensin-converting enzyme inhibitors, all of which induce comparable sodium appetite (5), both strains show greatly increased intakes of $\mathrm{NaCl}$ at all concentrations (and slightly decreased water intake; data not shown) and a resultant expansion in the range of preferred $\mathrm{NaCl}$ concentrations. Note also that the absolute increase of $\mathrm{NaCl}$ intake is comparable in the two strains across the full concentration range.

Nonetheless, the most usual procedure to ensure a specific appetite in a depleted rat is to offer a concentrated solution of $\mathrm{NaCl}$ so that most if not all of the intake that occurs cannot be ascribed to a basal preference. It is this type of procedure that has led investigators to report overconsumption after depletion (2). However, rats lose $\sim 2 \mathrm{mEq}$ of sodium after furosemide, so that repletion would correspond to ingestion of only $\sim 4$ $\mathrm{mL} 450 \mathrm{mM} \mathrm{NaCl}$, and this intake often occurs within less than $5 \mathrm{~min}$ after presentation of salt. Possibly slowing the intake (9) or offering a less "solute dense" (i.e., diluted) version of $\mathrm{NaCl}$ might allow rats to exhibit appropriate intake. To determine this, we examined the characteristics of intake of a high $(300 \mathrm{mM})$ and low $(30 \mathrm{mM}) \mathrm{NaCl}$ solution in rats treated $24 \mathrm{~h}$ previously with furosemide, timed so that the test began at lights out (10). Repletion would correspond to ingestion of 6-7 mL $300 \mathrm{mM}$ and 60-70 $\mathrm{mL} 30 \mathrm{mM} \mathrm{NaCl}$. Rats clearly cannot consume the latter amount within a short period of time. The results are shown in Table 1 . Rats with access to $300 \mathrm{mM} \mathrm{NaCl}$ consumed about two times their deficit in the first hour of access, went into a positive sodium balance, and continued to drink $\mathrm{NaCl}$ throughout the night, thus sustaining an even higher positive balance. There was no further increase in the intake of $300 \mathrm{mM} \mathrm{NaCl}$ when the test was repeated one week later, a finding that has also been reported by others (11).

In contrast, rats with access to $30 \mathrm{mM}$ $\mathrm{NaCl}$ were unable to consume the high volume required to repair their deficit in the first hour, but first-hour intake was increased on the second week compared with the first. In the first test, after $12 \mathrm{~h}$ rats were still in negative balance, but had repaired their deficit within $12 \mathrm{~h}$ at the second test one week later (10).

A parallel study of plasma markers of sodium depletion in rats drinking $30 \mathrm{mM}$ $\mathrm{NaCl}$ (Table 2) showed that the elevations in hematocrit ratio, plasma protein concentration, and renin activity were restored to normal after intake of $60-80 \mathrm{~mL}$ or $\sim 2 \mathrm{mEq} 30$ $\mathrm{mM} \mathrm{NaCl}$; this intake took place within the 6- to 12-h time frame. In contrast, plasma levels of aldosterone were decreased to nor-

Table 1. Intakes of 30 and $300 \mathrm{mM} \mathrm{NaCl}$ by sodium-depleted rats.

\begin{tabular}{lcccccc}
\hline Group & $\begin{array}{c}\text { First } \\
\text { hour }(\mathrm{mL})\end{array}$ & $\begin{array}{c}0-12 \mathrm{~h} \text { First hour } \\
(\mathrm{mL})\end{array}$ & $\begin{array}{c}0-12 \mathrm{~h} \\
(\mathrm{mEq})\end{array}$ & $\begin{array}{c}\text { Est. 1 h } \\
(\mathrm{mEq})\end{array}$ & $\begin{array}{c}\text { Est. 12 h } \\
\mathrm{Na}^{+} \text {balance } \\
(\mathrm{mEq})\end{array}$ & $\begin{array}{c}\mathrm{Na}^{+} \text {balance } \\
(\mathrm{mEq})\end{array}$ \\
\hline $30 \mathrm{mM}$ (1 week) & 13 & 33 & 0.4 & 1.0 & -1.6 & -1.0 \\
$300 \mathrm{mM}(1$ week) & 13 & 33 & 3.9 & 9.9 & +1.9 & +5.0 \\
$30 \mathrm{mM}$ (2 weeks) & $30^{*}$ & $83^{*}$ & $0.9^{*}$ & $2.4^{*}$ & -1.1 & +0.4 \\
$300 \mathrm{mM}$ (2 weeks) & 14 & 33 & 4.2 & 9.9 & +2.2 & +3.0 \\
\hline
\end{tabular}

Data from Rowland and Fregly (10). Est = estimated.

*Significant increase in intake from week 1 to 2 ( $P<0.05$; paired $t$-test).

Table 2. Changes in mean plasma parameters during slow repletion of sodium deficit in rats drinking $30 \mathrm{mM} \mathrm{NaCl}$.

\begin{tabular}{lcccc}
\hline Repletion time & $0 \mathrm{~h}$ & $1 \mathrm{~h}$ & $6 \mathrm{~h}$ & $12 \mathrm{~h}$ \\
\hline Cumulative intake $(\mathrm{mEq})$ & 0 & 0.4 & 1.8 & 2.4 \\
Aldosterone $(\mathrm{pg} / \mathrm{mL})$ & $356^{*}$ & 114 & $26^{+}$ & $35^{+}$ \\
Renin activity $\left(\mathrm{ng} \mathrm{Ang} \mathrm{I} \mathrm{mL}^{-1} \mathrm{~h}^{-1}\right)$ & $23.4^{*}$ & $14.2^{*}$ & 6.2 & 5.4 \\
Hematocrit ratio (\%) & $54.4^{*}$ & 51.0 & 50.5 & 50.6 \\
Protein concentration (g/dL) & $9.1^{*}$ & $8.7^{*}$ & 8.0 & 8.4 \\
\hline
\end{tabular}

Male rats were injected with furosemide and were placed on a sodium-deficient diet 24 h earlier. Data are reported as means for $\mathrm{N}=6$; data from Rowland and Fregly (10). Ang I = angiotensin I. Significantly above $\left(^{*}\right)$ or below $\left(^{+}\right)$typical values of these plasma parameters in non-depleted rats in our laboratory. 
mal after $1 \mathrm{~h}$ when the rats were still in a negative sodium balance, and were reduced to levels well below normal after 6 and $12 \mathrm{~h}$. This suggests that pre-absorptive factors such as taste may be important in reducing aldosterone synthesis, an idea also suggested by Tordoff and McCaughey (9) on the basis of sham intake studies.

To summarize this study, the satiation of sodium appetite after $\sim 12 \mathrm{~h}$ in rats drinking diluted $\mathrm{NaCl}$ suggests that spreading the ingestion out in time may contribute to satiation. This idea is not inconsistent with the results of studies reporting intake of concentrated $\mathrm{NaCl}$ in rats after either gavage or oral preloads $(9,12)$.

\section{Temporal maturation of appetite}

Jalowiec (2) originally noted that the intake of hypertonic $\mathrm{NaCl}$ studied $24 \mathrm{~h}$ after depletion with furosemide exceeded physiological need. Since that need is fully realized within $2 \mathrm{~h}$ and does not increase appreciably thereafter (2), it follows that over the course of $24 \mathrm{~h}$ the appetite must mature and at some time shorter than $24 \mathrm{~h}$ must have equaled physiological need. To examine this, Rowland and Morian (13) studied intake 3, 12 , and $24 \mathrm{~h}$ after injection of furosemide
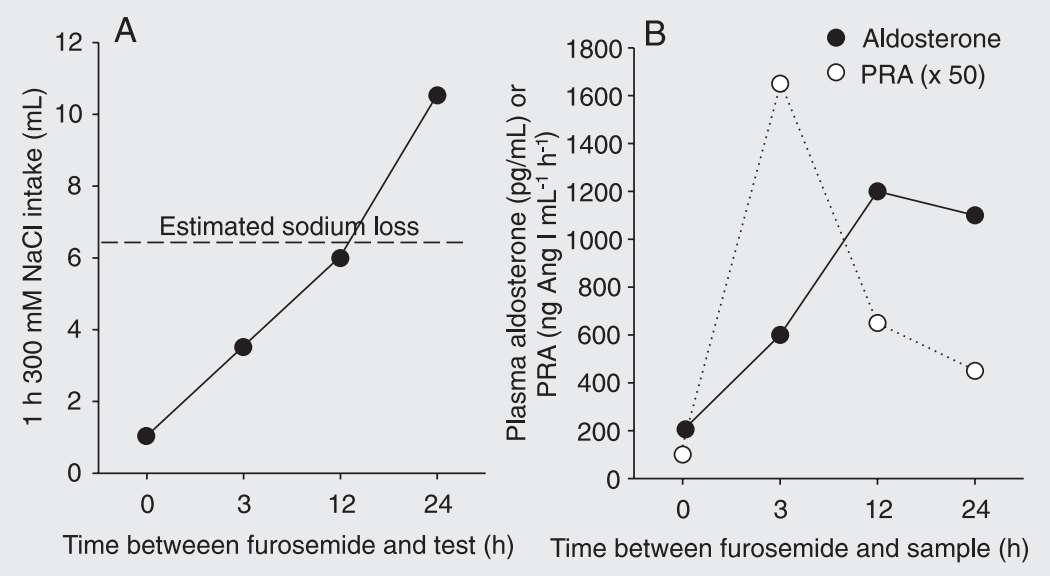

Figure 2. Temporal changes in sodium appetite (A) and plasma aldosterone or plasma renin activity (PRA; B) following a single injection of furosemide in rats. Data are reported as means for 6 male SD rats. Data are redrawn from Rowland and Morian (13). Ang I = angiotensin I. and on three consecutive tests held at 1week intervals so that animals might have the opportunity to learn an earlier appetite. The mean intakes of $300 \mathrm{mM} \mathrm{NaCl}$ in a 1-h test after these time delays are shown in the left panel of Figure 2. The intake reached estimated sodium loss after about 12-h injection-to-test interval, and there was no conditioning to consume sooner on subsequent weeks.

Measures of plasma aldosterone concentration and plasma renin activity (PRA), using the same protocol, are shown in Figure 2B. Aldosterone levels did not peak for $\sim 12$ $\mathrm{h}$, and so correlated with the growth of appetite. In contrast, PRA peaked at the earliest point and decreased at the later times, and therefore was not correlated with appetite. This temporal correlation between aldosterone and sodium appetite does not reflect causality because we found that treatment with metyrapone, a selective inhibitor of aldosterone synthesis that was fully effective to block elevations in plasma aldosterone, was without effect on the induced sodium appetite.

Several conclusions may be drawn from these data as they relate to overconsumption: overconsumption (of $300 \mathrm{mM} \mathrm{NaCl}$ ) occurs after $>12 \mathrm{~h}$ have elapsed since furosemide administration; at this time, aldosterone levels have peaked, but PRA is declining; however, blocking the rise in aldosterone with metyrapone did not affect appetite; while this study failed to identify any one "excitatory" factor for sodium appetite, we raised the possibility that maturation/ sensitization may reflect dissipation of an inhibitory factor (14). Scholars of sodium appetite have argued that since mature appetite in the face of an acute need takes hours to develop, then one might expect that the appetite would wane with a similar time course. Wolf et al. (12) reported studies consistent with this interpretation, and in the Rowland and Fregly study (10) reported above, appetite stopped after $12 \mathrm{~h}$ regardless of sodium 
balance. However, in both cases the interpretation was confounded because the offset of appetite often coincides with the onset of the light phase. In other studies, light or circadian rhythm has been shown to modulate sodium appetite strongly (15).

We note that the "slow offset" argument makes little ecological sense - why would natural selection have retained a behavior that puts the animal in danger by foraging for a commodity long after the need was met? Perhaps the problem is not with the sensing (or deficiency therein) of sodium balance but rather with the environment in which we test appetite. While animals at natural risk for sodium depletion (e.g., herbivores) may find concentrated mineral deposits (salt licks), these locations not only require effort to reach but also are quite likely to become a magnet for potential predators. The environment may provide significant inhibitory factors, and we now turn to that analysis.

\section{Effort-operant responding for salt}

We initially drew on protocols from the domain of food and in particular the continuous access closed economy work of Collier (16). To translate this to sodium appetite, we needed to use a protocol in which an "on" signal would be present most of the time, and we could then examine the temporal self-organization of salt appetite. We (17) chose chronic administration of DOCA. Rats were tested in a protocol with three procurement cost phases (1, 80, 300 presses), three $\mathrm{NaCl}$ concentration phases $(40,150,400$ $\mathrm{mM}$ ), and two treatment phases (baseline and DOCA), with each phase lasting 1-3 weeks. Rats were required to emit the designated procurement cost on one of two levers. One lever delivered distilled water and the other $\mathrm{NaCl}$ of the designated concentration. Completion of the cost ratio caused the relevant spout to be moved on a motor-driven platform into reach of the rat through a slot above the lever. The rat could then lick and drink as much as it chose but with the caveat that whenever 10 min elapsed without a lick (detected by a contact sensor) the motor moved the bottle out of reach until the next procurement ratio was completed.

In terms of preference for water compared with $\mathrm{NaCl}$, the baseline data showed a typical preference aversion function, with greatest $\mathrm{NaCl}$ choice at $150 \mathrm{mM}$. As procurement cost increased, rats took fewer and larger bouts of either $\mathrm{NaCl}$ or water (Table 3). Comparing baseline to DOCA phases, rats took more $\mathrm{NaCl}$ during the DOCA phase. In other words, rats initiated more salt bouts during the DOCA phase (17).

Despite this encouraging result, this protocol is not very useful in terms of examining our goal of studying intake in relationship to defined physiological need - i.e., a true "economic decision". Thus, our next approach was to use this protocol but with a chronic natriuretic regimen. We (Colbert CL and Rowland NE, unpublished data) used hydrochlorothiazide (HCZ) in the diet. Fregly and $\mathrm{Kim}$ (18) had reported that HCZ induces higher intakes of $\mathrm{NaHCO}_{3}$ than $\mathrm{NaCl}$, an event which we verified in a proof-of-principle experiment (19). In the foraging protocol, the result was similar to the DOCA study, with rats initiating more salt bouts under HCZ than at baseline, and with bout sizes increasing at higher procurement costs (Table 3). But it proved difficult to predict or control the timing and magnitude of the physiological deficit induced by the HCZ, hence to make arguments about satiation of need.

Thus, in our most recent studies (20) we returned to the furosemide protocol discussed earlier but instead of using continuous access procurement costs we used a time-limited access with imposed consummatory cost and a closed economy since this was the only salt the animals could obtain to alleviate their need. The protocol, in which furosemide was injected once every day, is 
sketched below.

Furosemide $\stackrel{\sim 18 \mathrm{~h}}{\longrightarrow}$ Operant $(\mathrm{PR}) \mathrm{NaCl}$ session $\stackrel{\sim 4 \mathrm{~h}}{\longrightarrow}$ Furosemide,

where PR is a progressive ratio.

This protocol allows for an accurate timing of the sodium loss, and $18 \mathrm{~h}$ is sufficient

Table 3. Performance of rats in a closed economy procurement foraging task for salt solution.

Bouts/day Bouts/day Bout size Bout size Intake Intake

$(\mathrm{PFR}=1) \quad(\mathrm{PFR}=300) \quad\left(\right.$ licks $\left.\times 10^{3}\right) \quad\left(\right.$ licks $\left.\times 10^{3}\right) \quad(\mathrm{mL} /$ day $) \quad(\mathrm{mL} /$ day $)$

$(P F R=1) \quad(P F R=300) \quad(P F R=1) \quad(P F R=300)$

\begin{tabular}{|c|c|c|c|c|c|c|}
\hline \multicolumn{7}{|l|}{ Study A } \\
\hline Basal $40 \mathrm{mM} \mathrm{NaCl}$ & 20 & 1 & 0.5 & 1.5 & 23.5 & 8.3 \\
\hline Basal $150 \mathrm{mM} \mathrm{NaCl}$ & 5 & 1 & 0.5 & 1.5 & 12.2 & 7.7 \\
\hline Basal $400 \mathrm{mM} \mathrm{NaCl}$ & 1 & 1 & 0.2 & 0.2 & 0.8 & 1.2 \\
\hline DOCA $40 \mathrm{mM} \mathrm{NaCl}$ & 13 & 4 & 0.8 & 2.2 & 50.5 & 46.4 \\
\hline DOCA $150 \mathrm{mM} \mathrm{NaCl}$ & 12 & 3 & 1.5 & 2.6 & 85.7 & 38.4 \\
\hline DOCA $400 \mathrm{mM} \mathrm{NaCl}$ & 8 & 1 & 1.0 & 1.4 & 47.6 & 8.7 \\
\hline \multicolumn{7}{|l|}{ Study B } \\
\hline Basal $300 \mathrm{mM} \mathrm{NaHCO} 3$ & 3 & 0 & 0.3 & 0 & 4.5 & 0 \\
\hline $\mathrm{HCZ}_{300 \mathrm{mM} \mathrm{NaHCO}}$ & 17 & 4 & 0.6 & 1.7 & 51.0 & 34.0 \\
\hline
\end{tabular}

Study A, Data from Colbert and Rowland (17); data are reported as rounded means (several days of stable behavior) for $\mathrm{N}=4$ male Sprague-Dawley rats from procurement fixed ratio (PFR) 1 and 300 conditions. The intakes were calculated on the basis of $1 \mathrm{~mL}=200$ licks. Study $B$, Unpublished data (Colbert CL and Rowland NE, 2003-4). Four male Long-Evans rats were fed either low sodium chow (basal condition) or low sodium chow with $0.6 \mathrm{~g}$ hydrochlorothiazide $(\mathrm{HCZ})$ added $/ \mathrm{kg}$.
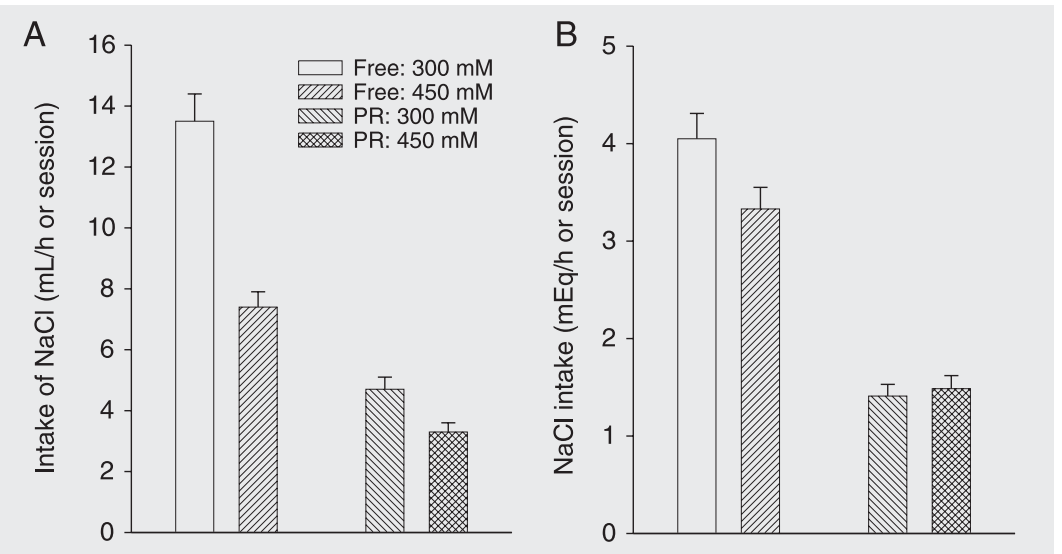

Figure 3. Intake in $\mathrm{mL}(\mathrm{A})$ and $\mathrm{mEq}(\mathrm{B})$ of rats drinking either 300 or $450 \mathrm{mM} \mathrm{NaCl} \sim 18 \mathrm{~h}$ after sodium depletion with furosemide and either drinking freely (1-h session) or under progressive ratio (PR) session conditions (terminated after $15 \mathrm{~min}$ of no responding, typically after $\sim 1 \mathrm{~h}$ ). Data are reported as means \pm SEM. The estimated sodium loss prior to the drinking session is $1-2 \mathrm{mEq}$; intake approximates the need in the PR protocol. to allow complete maturation of the appetite. A few hours after the operant session in which $\mathrm{NaCl}$ was available, furosemide was injected and the cycle began again. Rats were fed a low sodium diet throughout. We chose PR schedules to study satiation by analogy with their use as a particularly sensitive metric of motivation for drug taking (21). In a PR, each successive reinforcer costs more (i.e., incrementing consummatory cost), so this is really a special instance of a variable ratio schedule, but one in which rats show a break point when they cease responding. In terms of food, this is analogous to foraging causing resource depletion in a patch, when animals are forced to make 'optimal' decisions about staying versus leaving the patch.

We chose two PR schedules differing in step size for successive reinforcers but the intakes were similar and so have been combined for presentation. Additionally, using the motor-driven salt bottles mentioned above, access was granted for either a short (7.5 s) or a long (15 s) duration: continuous licking for these durations would yield $\sim 0.3$ and $0.6 \mathrm{~mL}$, respectively. Only data for the short duration are shown: these were approximately $73 \%$ of the intakes in the long duration and so represent the lowest intakes that we observed. Further, we ran two studies, one using $300 \mathrm{mM} \mathrm{NaCl}$ and the other $450 \mathrm{mM} \mathrm{NaCl}$. As a control, animals with free access to either 300 or $450 \mathrm{mM}$ were run in the same depletion protocol.

The results are shown in Figure 3. Control rats with free access consumed a greater volume of 300 than $450 \mathrm{mM} \mathrm{NaCl}$, and slightly more when converted to solute. Both intakes were considerably in excess of the 1.5-2.0 mEq deficit that we estimated. The intakes of rats tested in the PR were less than $50 \%$ those in the free drink condition, and when converted to $\mathrm{mEq}$. Note that rats with the longer access PR reinforcer consumed $\sim 2 \mathrm{mEq}$. In another study, we determined that the actual sodium loss in this protocol 
was $1-2 \mathrm{mEq}$ and therefore we concluded that the PR rats showed a break point near their physiological need. We again emphasize that the break point was not imposed either by experimenter or time: the criterion for ending the session was 15 min elapsed since the last reinforcer. Thus, rats showed satiation by a standard criterion for establishing meals and satiety.

To determine whether this intake in the PR session caused physiological changes by the time that satiation occurred, blood was taken from rats either before their PR session (pre) or after satiating in the PR session (post; run in the $300 \mathrm{mM}$ short protocol as in Figure 3), or when not depleted (control). It can be seen in Table 4 that depleted (presession) rats had expected significant elevations in hematocrit ratio, plasma protein, PRA, and aldosterone. Each of these parameters was significantly reduced by the end of the PR session. It is also noteworthy that aldosterone was normalized fully at this time while PRA was not, a result similar to the more rapid drop of aldosterone in the $30 \mathrm{mM}$ $\mathrm{NaCl}$ free drinking study reported above (10).

Thus, behavioral satiation by the PR break point criterion occurs when physiological need, assessed by hematocrit ratio, protein, and aldosterone, is largely alleviated. There is no hint of overconsumption (Figure 2, and verified in this particular blood sampling study).

\section{Discussion}

Collectively, the data presented above show that behavioral satiation for salt depends on the circumstances under which salt is presented, and not on some immutable target amount of solute. In particular, the development of the repeated furosemide model allows us to make an accurate assessment of physiological need. Using a PR schedule, we showed that behavioral satiation is critically dependent on motivational and economic factors that are imparted in a PR. It appears that the motive force to consume when there is little or no cost involved in obtaining the commodity leads to overconsumption, whereas under harder conditions the intake matches the need reasonably accurately.

The term motivation implies the effort of an organism in the face of environmental adversity (22) and quite early studies of sodium appetite in rats modeled adversity in the form of operant lever pressing. At that time, the understanding of the physiology of sodium appetite was rudimentary and procedures for producing sodium appetite were either painful (formalin injection) or induced an irreversible condition (adrenalectomy). Almost all recent studies have used unpalatable hypertonic solutions of sodium salts as the adversity, in part because this is procedurally easier and requires little or no training compared with operant tasks.

Consumption of a commodity is inversely related to environmental adversity or effort (23), so it follows that a control system so constructed could produce consumption in excess of need when the environment was favorable and in the absence of a strong endogenous signal for satiation. The results of the present PR experiment, as well as a few literature reports, are consistent with this perspective. Thus, McCutcheon and Levy (24) found that formalin-treated rats bar pressing in a variable interval 20-s schedule

Table 4. Plasma parameters of furosemide-treated rats taken either before (pre) or after (post) satiation in the plasma renin protocol.

\begin{tabular}{|c|c|c|c|}
\hline & Control & Pre-session & Post-session \\
\hline Hematocrit ratio (\%) & $44.1 \pm 0.5$ & $48.4 \pm 1.1^{*}$ & $45.4 \pm 0.4^{+}$ \\
\hline Plasma protein (g/dL) & $8.5 \pm 0.2$ & $9.2 \pm 0.2^{*}$ & $8.4 \pm 0.2^{+}$ \\
\hline Aldosterone (pg/mL) & $500 \pm 75$ & $2320 \pm 300^{*}$ & $600 \pm 80^{+}$ \\
\hline Renin activity (ng Ang I mL $\mathrm{m}^{-1} \mathrm{~h}^{-1}$ at $37^{\circ} \mathrm{C}$ ) & $6.5 \pm 0.8$ & $29.5 \pm 4.5^{\star}$ & $19.0 \pm 2.0^{*+}$ \\
\hline
\end{tabular}


for $400 \mathrm{mM} \mathrm{NaCl}$ solution showed a defined temporal onset and satiation of behavior when $\mathrm{NaCl}$ was available ad libitum. Economidou et al. (25) recently reported a protocol similar to our own using chronic furosemide treatment and daily operant access to $\mathrm{NaCl}$. Their rats consumed $\sim 18 \mathrm{~mL} 2 \% \mathrm{NaCl}(\sim 3.6$ $\mathrm{mEq})$, well in excess of need, when it was available in $0.1-\mathrm{mL}$ reinforcements on an FR1. But this is a very easy schedule of procurement and therefore, together with the data reviewed above, we suggest that the propensity of rats to overconsume in foraging protocols may be critically dependent on how difficult the task is and/or how it is structured in time. Satiation and satiety then may be considered to be variable constructs, dependent on both internal and economic factors (16). The salt depletion protocol here developed allows for a quantitative investigation of this hypothesis as it relates to physiological need.

\section{References}

1. Daniels D, Fluharty SJ. Salt appetite: a neurohormonal viewpoint. Physiol Behav 2004; 81: 319-337.

2. Jalowiec JE. Sodium appetite elicited by furosemide: effects of differential dietary maintenance. Behav Biol 1974; 10: 313-327.

3. DeSimone JA, Ferrell F. Analysis of amiloride inhibition of chorda tympani taste response of rat to $\mathrm{NaCl}$. Am J Physiol 1985; 249: R52R61.

4. Wolf G, McGovern JF, Dicara LV. Sodium appetite: some conceptual and methodologic aspects of a model drive system. Behav Biol 1974; 10: 27-42.

5. Rowland NE, Fregly MJ. Sodium appetite: species and strain differences and role of renin-angiotensin-aldosterone system. Appetite 1988; 11: 143-178.

6. Rowland NE, Fregly MJ. Regulation of intakes of water and $\mathrm{NaCl}$ solutions in Fischer 344 rats: contrasts and comparisons between strains. Physiol Behav 1988; 44: 461-467.

7. Bachmanov AA, Beauchamp GK, Tordoff MG. Voluntary consumption of $\mathrm{NaCl}, \mathrm{KCl}, \mathrm{CaCl}_{2}$, and $\mathrm{NH}_{4} \mathrm{Cl}$ solutions by 28 mouse strains. Behav Genet 2002; 32: 445-457.

8. Fregly MJ. Effect of the angiotensin converting enzyme inhibitor, captopril, on $\mathrm{NaCl}$ appetite of rats. J Pharmacol Exp Ther 1980; 215: 407-412.

9. Tordoff MG, McCaughey SA. Influence of oral and gastric $\mathrm{NaCl}$ preloads on $\mathrm{NaCl}$ intake and gastric emptying of sodium-deficient rats. Am J Physiol Regul Integr Comp Physiol 2001; 281: R1152R1160.

10. Rowland NE, Fregly MJ. Repletion of acute sodium deficit in rats drinking either low or high concentrations of sodium chloride solution. Am J Physiol 1992; 262: R419-R425.

11. Leshem M, Kavushansky A, Devys JM, Thornton S. Enhancement revisited: the effects of multiple depletions on sodium intake in rats vary with strain, substrain, and gender. Physiol Behav 2004; 82: 571-580.

12. Wolf G, Schulkin J, Simson PE. Multiple factors in the satiation of salt appetite. Behav Neurosci 1984; 98: 661-673.

13. Rowland NE, Morian KR. Roles of aldosterone and angiotensin in maturation of sodium appetite in furosemide-treated rats. $A m \mathrm{~J}$ Physiol 1999; 276: R1453-R1460.

14. Verbalis JG, Blackburn RE, Olson BR, Stricker EM. Central oxytocin inhibition of food and salt ingestion: a mechanism for intake regulation of solute homeostasis. Regul Pept 1993; 45: 149-154.

15. Rowland NE, Bellush LL, Fregly MJ. Nycthemeral rhythms and sodium chloride appetite in rats. Am J Physiol 1985; 249: R375R378.

16. Collier GH. Satiety: an ecological perspective. Brain Res Bull 1985; 14: 693-700.

17. Colbert CL, Rowland NE. Sodium preference and appetite in rats in an operant protocol. Physiol Behav 2005; 83: 715-721.

18. Fregly MJ, Kim KJ. Specificity of the sodium chloride appetite of hydrochlorothiazide-treated rats. Physiol Behav 1970; 5: 595-599.

19. Rowland NE, Colbert CL. Sodium appetite induced in rats by chronic administration of a thiazide diuretic. Physiol Behav 2003; 79: 613619.

20. Starr LJ, Rowland NE. Characteristics of salt appetite in chronically sodium-depleted rats using a progressive ratio schedule of procurement. Physiol Behav 2006; 88: 433-442.

21. Stafford D, LeSage MG, Glowa JR. Progressive-ratio schedules of drug delivery in the analysis of drug self-administration: a review. Psychopharmacology 1998; 139: 169-184.

22. Epstein AN. Instinct and motivation as explanations for complex behavior. In: Pfaff DW (Editor), The physiological mechanisms of motivation. New York: Springer-Verlag; 1982. p 25-58.

23. Houston Al, McNamara JM. The value of food: effects of open and closed economies. Animal Behav 1989; 37: 546-562.

24. McCutcheon B, Levy C. Relationship between $\mathrm{NaCl}$ rewarded barpressing and duration of sodium deficiency. Physiol Behav 1972; 8: 761-763.

25. Economidou D, Mattioli L, Cifani C, Perfumi M, Massi M, Cuomo V, et al. Effect of the cannabinoid CB1 receptor antagonist SR-141716A on ethanol self-administration and ethanol-seeking behaviour in rats. Psychopharmacology 2006; 183: 394-403. 